\title{
STUDY ON SPATIAL STRESS EFFECT OF PC CONTINUOUS THIN-WALLED BOX GIRDER BRIDGE
}

\author{
Shulin Zhou' ${ }^{1}$ Honglei Zhang ${ }^{2}$
}

\author{
1. Highway Development Center of Guangxi Zhuang Autonomous Region, \\ Maintenance Department, Nanning, No.3 Yunjing Road, PR of China; \\ 317880950@qq.com \\ 2. Beijing Xinqiao Technology Development Co., Ltd, Bridges and Tunnels \\ Department, Beijing, No.8 Xitucheng, PR of China; \\ Hongleizhang_Xq@163.com,765310906@qq.com
}

\begin{abstract}
In order to study the influence of spatial stress effect and shear lag effect on the cracking of PC continuous thin-walled box girder bridge, a spatial model was established by using ANSYS finite element software to analyze the internal stress distribution of the bridge. The test results are compared with the analysis results of spatial model and plane link system model through the load test of real bridge. The results show that the longitudinal stress is evenly distributed along the width direction, which means that the spatial stress effect and the shear lag effect have little influence on the downdeflection of the bridge. The shear lag coefficient at the longitudinal axis of midspan bottom plate and the intersection of bottom plate and web are larger than other positions, which is most likely to produce cracks caused by stress concentration and should be strengthened here in practical engineering. The results of load test show that the results of spatial finite element analysis are more reliable than those of plane link system calculation, and the design and construction based on the results of spatial finite element analysis is safer.
\end{abstract}

\section{KEYWORDS}

Thin-walled box girder bridge, Spatial stress effect, Shear lag effect, Load test

\section{INTRODUCTION}

The PC continuous box girder has the advantages of strong span capacity, large structural stiffness, beautiful appearance, smooth deck and easy maintenance, and is widely used in bridge structures with large span [1]. However, the section of box girder belongs to thin-walled structure. According to the investigation, the prestressed continuous thin-walled box girder bridge has cracked in different degrees after a period of operation [2]. Therefore, it needs to be equipped with a lot of structural reinforcement. There are many reasons that affect the crack generation, such as prestress spatial distribution, shear lag effect, prestress loss, overload, etc. Therefore, appropriate space analysis theory of box girder should be adopted to analyze the crack resistance of box girder, focusing on analyzing the spatial stress effect of the structure, so as to reflect the spatial stress effect of box girde. Then we can accurately understand the crack resistance of box girder structure.

The spatial stress analysis methods of PC thin-walled box girder bridges can be divided into two categories: analytical method and numerical method. Based on the analytical method and from different perspectives, some scholars have proposed such approximate calculation methods as energy variation method, generalized coordinate method, analogy beam method and frame 


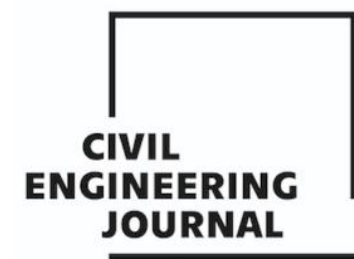

Article no. 48

THE CIVIL ENGINEERING JOURNAL 3-2021

analysis method for the calculation and analysis of torsion and distortion of box girder [3-5]. The calculation process of these methods is relatively complicated, and the calculation accuracy depends on the numerical solution accuracy of the differential equations. So, they are mostly applied to the research of the box-girder bridge with constant section, as the theoretical analysis results of the shear lag effect of the box girder with variable section are relatively few [6-7]. With the development of electronic computers, finite element method is very common in the analysis of box girder [8-12], such as Midas Civil, Adina, ANSYS and other structural linear and nonlinear finite element analysis software. With the help of computer finite element analysis, all the stresses on the box section, such as longitudinal bending stress, torsional warping stress, distorted warping stress, distorted transverse stress, shear lag and local load stress, can be obtained. By analyzing the data and results, researchers can accurately know the spatial stress distribution, magnitude and structural deformation of the components.

In this paper, a PC continuous thin-walled box girder bridge is selected as the research object. The finite element analysis software ANSYS is used to analyze the effect of spatial stress and shear lag on the deflection and cracking of the bridge. Through load tests, the fitting degree of spatial finite element model, plane beam analysis and test results is compared, so as to further verify the validity of spatial finite element model to analyze the spatial stress effect of PC continuous thin-walled box girder bridge. It provides reference for engineering practice.

\section{BACKGROUND}

The span of the bridge is $35 \mathrm{~m}+60 \mathrm{~m}+90 \mathrm{~m}+60 \mathrm{~m}+35 \mathrm{~m}$, and the width combination is 0.75 $\mathrm{m}+10.5 \mathrm{~m}+0.75 \mathrm{~m}$. The box girder is prestressed in longitudinal, horizontal and vertical directions, and the tensioning stress is $1290 \mathrm{MPa}$. Lateral view of the bridge is shown in Figure 1 and Figure

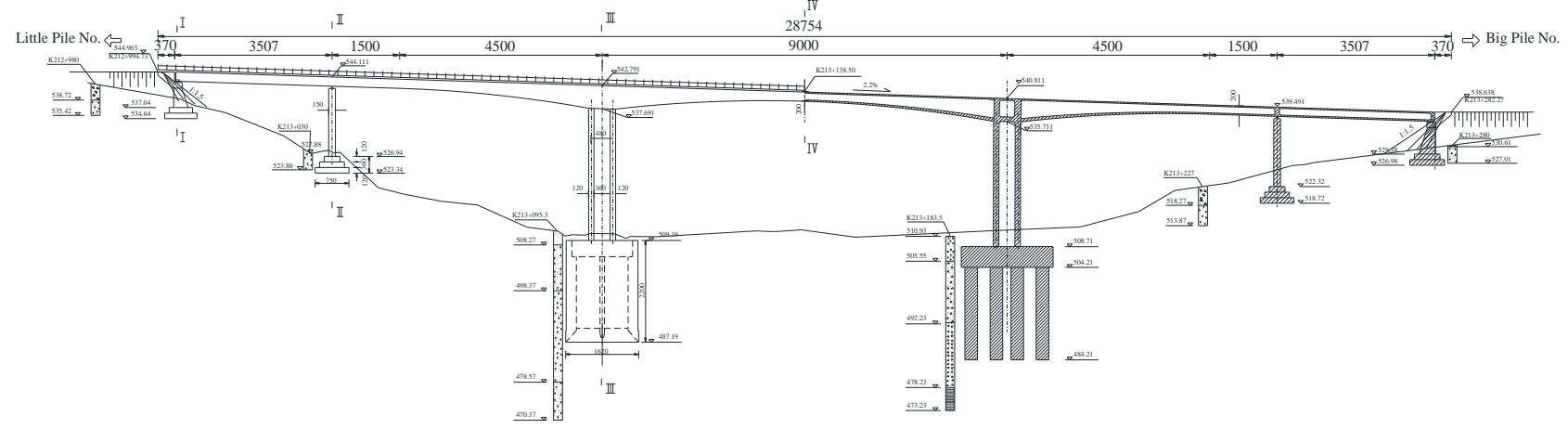

Fig. 1 - Lateral view of the bridge ( unit: $\mathrm{cm}$ ) 


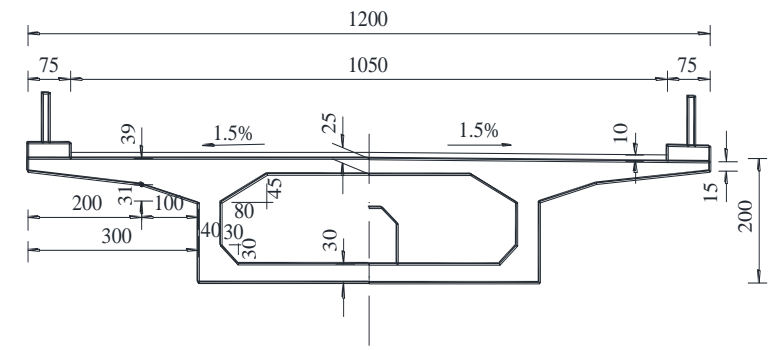

(a) I, II, IV

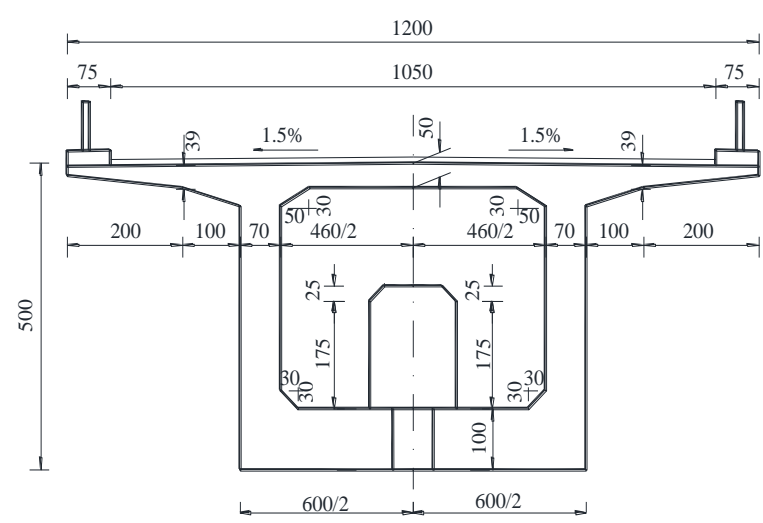

(b) III

Fig. 2 - Cross-section of the bridge (unit: $\mathrm{cm}$ )

\section{FINITE ELEMENT MODEL ANALYSIS}

Using ANSYS finite element software to establish the space solid finite element model, reinforced concrete structure using 8-node solid element SOLID 65, can well simulate the WilliamsWarnke strength theory based on the concrete three- direction force of the nonlinear response. Link8 unit is selected for prestressing tendon. Separate model is used to simulate the prestress in the model, and the longitudinal, vertical and transverse prestress tendons are separately modelled. Since the linear shape of the bottom flange is a quadratic parabola and there are many control nodes, this paper adopts the bottom-up modelling method, namely $\mathrm{K}-\mathrm{V}$ and $\mathrm{K}-\mathrm{L}$ modes. Considering the symmetry of the structure and load of the bridge, the model of the semi-full bridge is selected, which cannot only save the number of units and nodes, but also greatly save the calculation time. The model consists of 120,490 units and 165,435 nodes. In the model, $X$ coordinate represents the transverse bridge direction, $Y$ coordinate represents the vertical bridge direction, and $Z$ coordinate direction is the vertical bridge direction. The box girder concrete bulk density is calculated by $26 \mathrm{kN} / \mathrm{m}^{3}$, the guardrail load is calculated by $24 \mathrm{kN} / \mathrm{m}$.

According to the requirements of design specifications [13], the temperature load and the moving load were loaded according to the worst load condition of the mid-span bending moment of the main span. Working load includes deadweight, deck pavement weight, prestress, temperature gradient and moving load. The finite element model is shown in Figure 5.

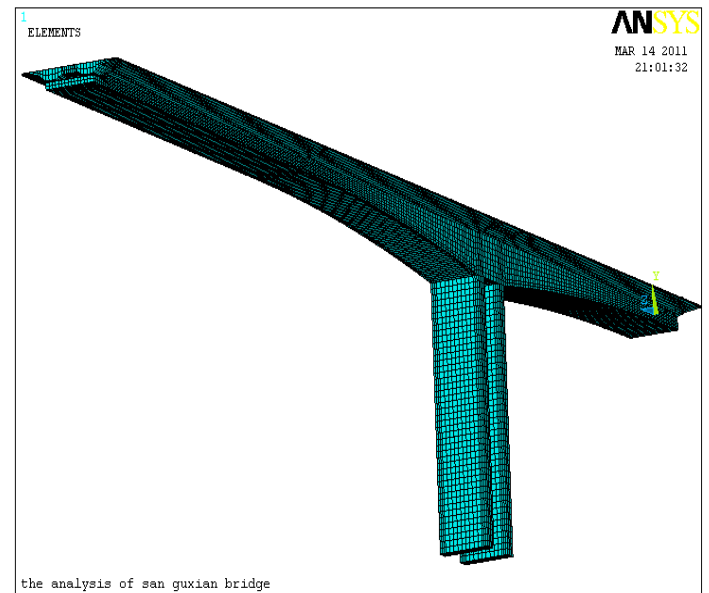

Fig. 3 - Finite element model of bridge

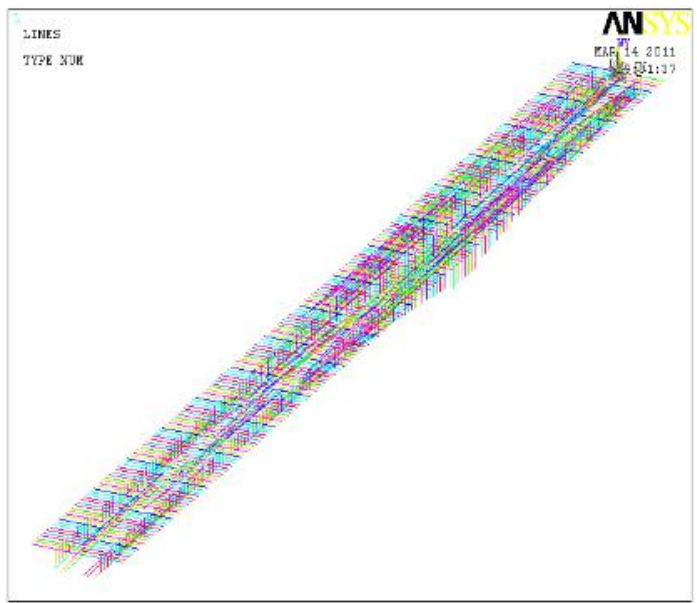

Fig. 4 - Finite element model of steel strand 


\section{ANALYSIS OF SPATIAL STRESS EFFECT}

\section{LONGITUDINAL STRESS}

The calculation results of the longitudinal stress of the bridge are shown in Figure 5 - Figure 8 . The top flange is under pressure as a whole, and the longitudinal stress increases from the beam end to the middle of the main span. The longitudinal stress of the top flange is distributed evenly along the width direction, and the difference is basically controlled within $0.8 \mathrm{MPa}$.

The longitudinal stress of the bottom flange is basically compressive stress, and the stress gradually increases from the pier to both sides of the longitudinal bridge. The longitudinal stress of bottom flange is evenly distributed along the width of the main span, but fluctuates greatly in the middle of the side span and the secondary side span, especially near the web. The transverse difference of other sections is basically within $1.0 \mathrm{MPa}$.

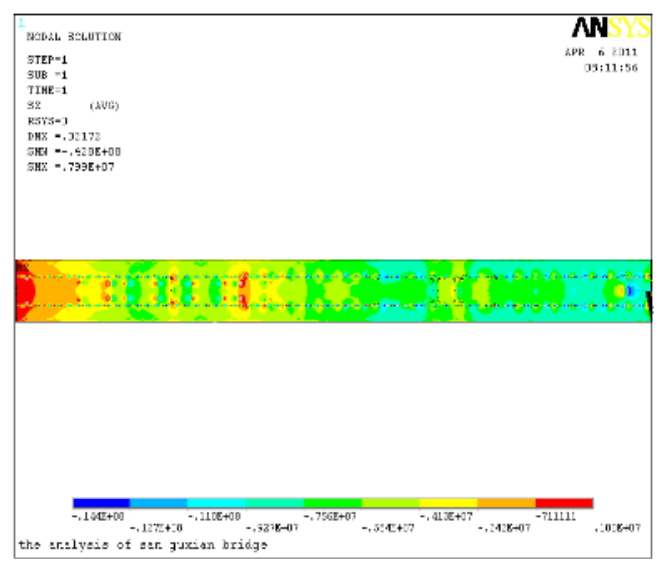

Fig. 5 - Top flange stress nephogram

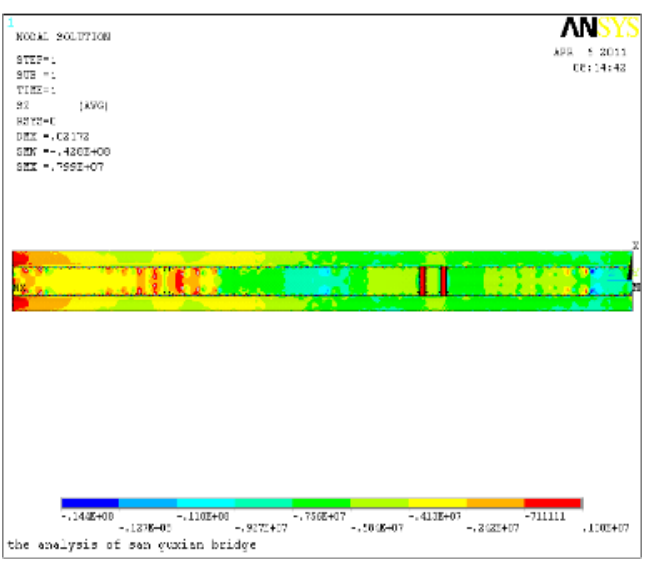

Fig. 6 - Bottom flange stress nephogram

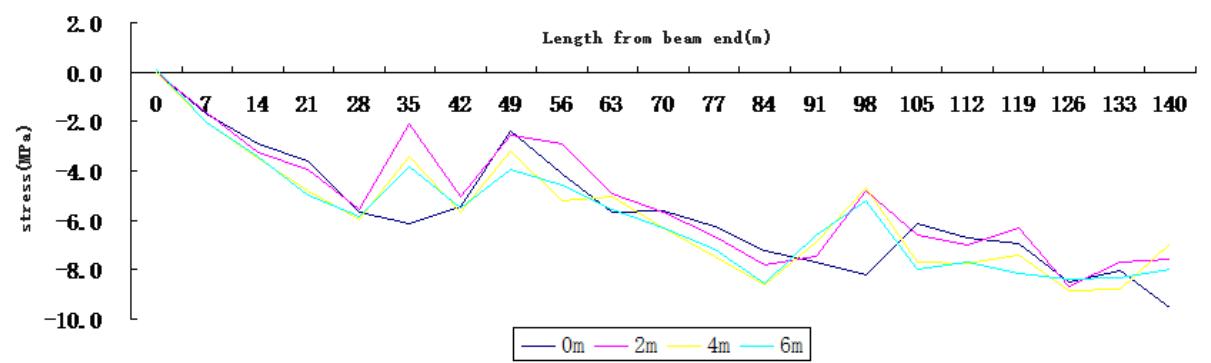

Fig. 7 - Transverse distribution of longitudinal stress along the top flange $(0,2,4,6$ represents the distance from the longitudinal axis )

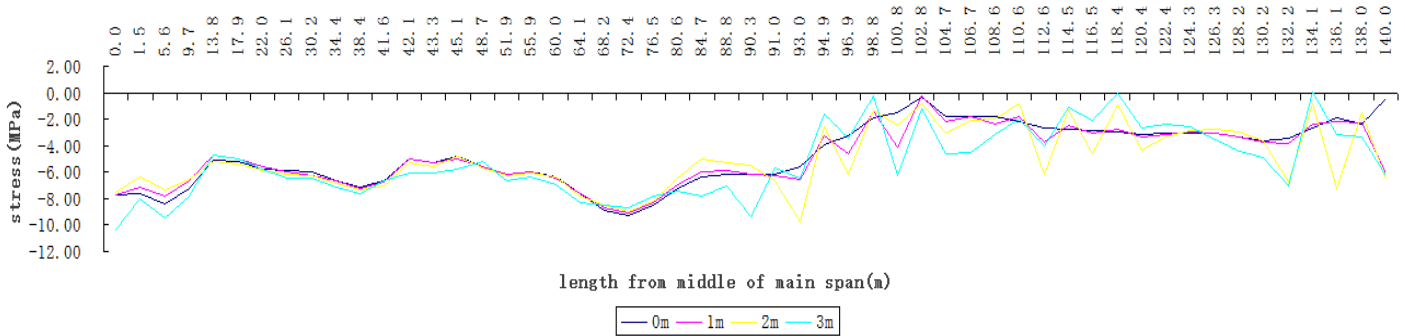

Fig. 8 - Transverse distribution of longitudinal stress along the bottom flange 


\section{PRINCIPAL STRESS}

The calculation results of principal stress are shown in Figure 9 - Figure 12. The principal stress of top flange is basically between $-0.3 \mathrm{MPa} \sim 2.5 \mathrm{MPa}$, except for the prestressed anchorage point with stress concentration. The stress distribution along the flange slab is more uniform. At the main pier, the stress changes within the range of webs, the maximum is about $2.5 \mathrm{MPa}$. The lateral distribution of principal stress along the bridge is that the longitudinal axis increases laterally. The principal stress range of bottom flange is $-1.0 \mathrm{MPa} 6.5 \mathrm{MPa}$. Due to the influence of shear lag, the principal stress decreases gradually from the longitudinal axis of the bottom flange to the web.

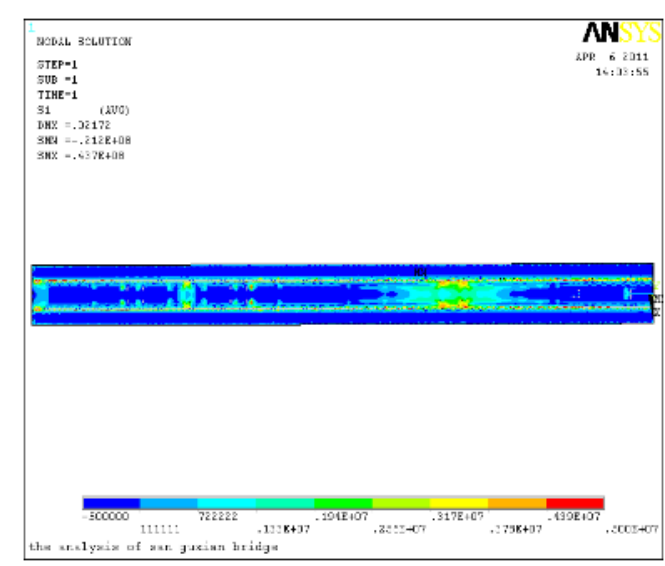

Fig. 9 - Top flange principal stress nephogram

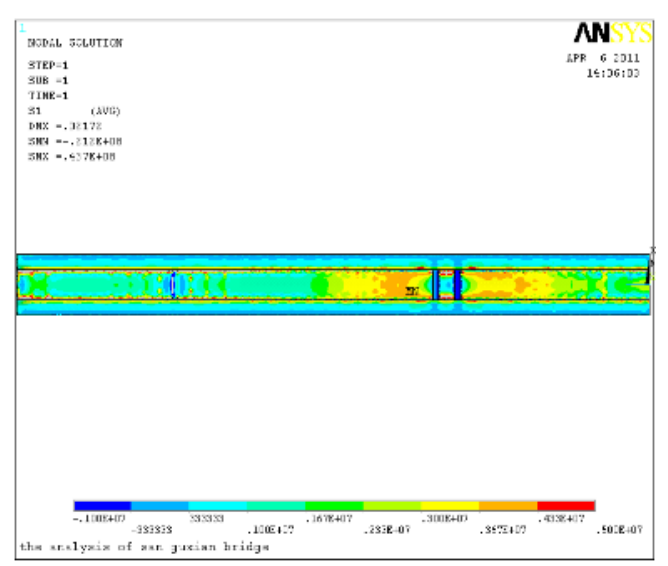

Fig. 10 - Bottom flange principal stress nephogram

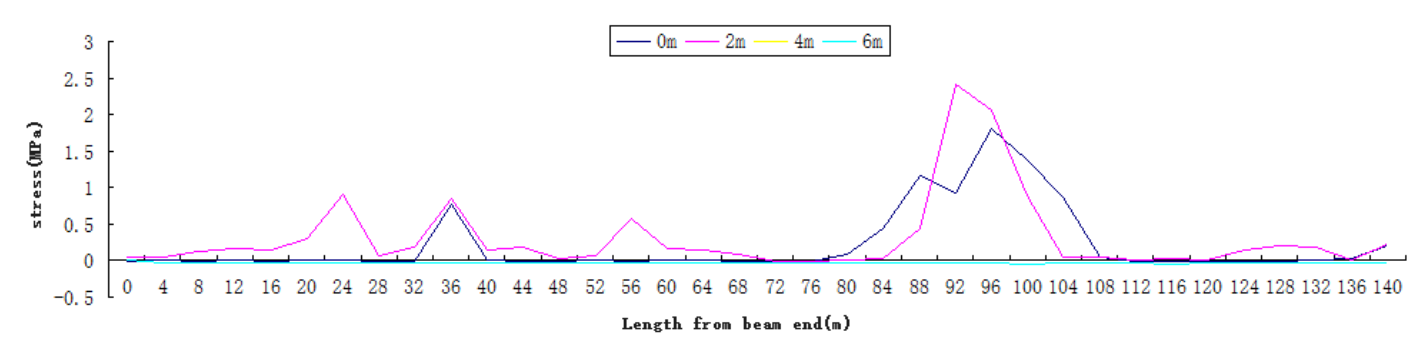

Fig. 11 - Transverse distribution of principal stress along the top flange

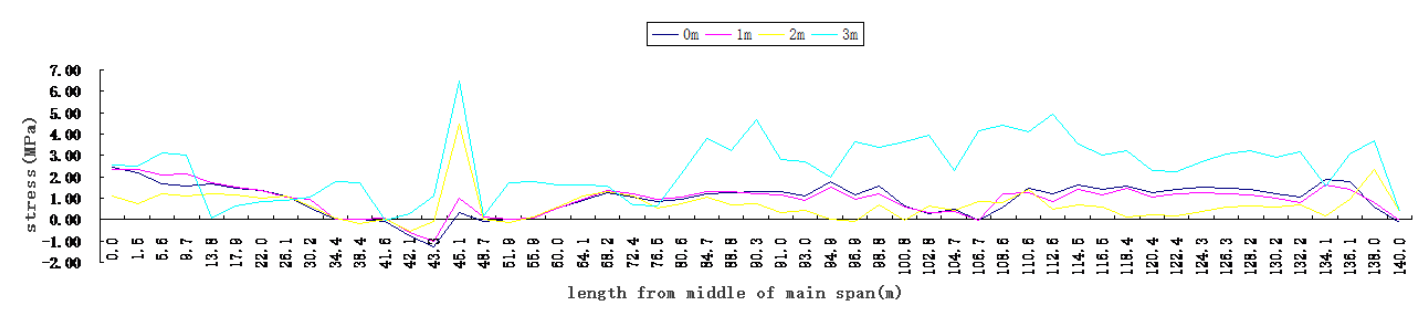

Fig. 12 - Transverse distribution of principal stress along the bottom flange 


\section{SHEAR LAG EFFECT}

In order to describe the influence of shear lag effect of box girder, the concept of shear lag coefficient is introduced in the project [14-15].

$$
\lambda=\frac{\text { real stress }}{\text { stress calculated according to elementary beam theory }}
$$

Under the effect of shear lag, the shear force transmits lag from the web to the flange slab, resulting in the uneven lateral distribution of normal stress. The actual longitudinal stress of the flange slab near the web is greater than the elementary beam theory calculation, which is called "positive shear lag effect". On the contrary, it is called "negative shear lag effect".

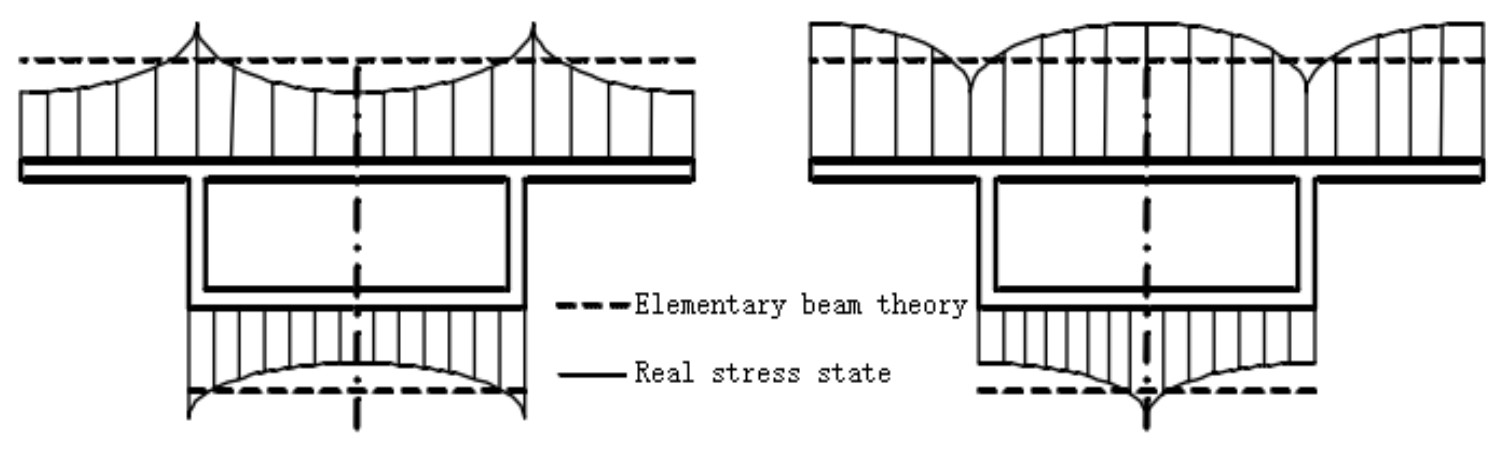

Fig.13 - Positive shear lag effect

Fig. 14 - Negative shear lag effect

Figure 15 and Figure 16 respectively show the distribution of longitudinal stress of the top and bottom flange in the middle of the main span along the transverse bridge direction. Figure 17 and Figure 18 are respectively longitudinal stress distribution diagrams of the top and bottom flange at main pier along the transverse bridge direction. It can be concluded that the top and bottom flange are in a state of compression, and the longitudinal stress distribution along the transverse is not uniform. The stress difference of the top flange at the middle of the main span is about 5.1 MPa, and that of the bottom flange is about 13.0 MPa. At the main pier, the stress difference of the top flange is $5.6 \mathrm{MPa}$, and that of the bottom flange is about $5.2 \mathrm{MPa}$.

Figure 19 and Figure 20 respectively show the shear lag coefficients of the top and bottom flange of the main span at middle. Figure 21 and Figure 22 show the top of the main pier top and bottom flange, respectively. It can be seen that the shear lag effect of these sections is positive. The shear lag coefficient of the top flange at midspan is between 0.7 and 1.7 , and that of bottom flange is between 0.85 and 1.6. As the main pier, the shear lag coefficient of top flange is between 0.8 and 1.65 , and that of bottom flange is between 0.8 and 1.82 .

In general, under the action of deadweight and prestress, the transverse difference of the longitudinal stress of the key sections and the dispersion degree of the shear lag coefficient is larger. Compared with the top flange, the dispersion degree of the shear lag coefficient in the same section is larger than that of the bottom flange. 


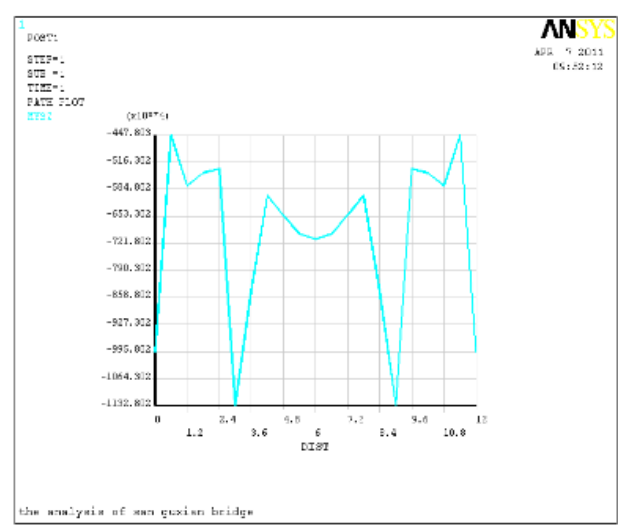

Fig. 15 - Longitudinal stress along the top flange of midspan

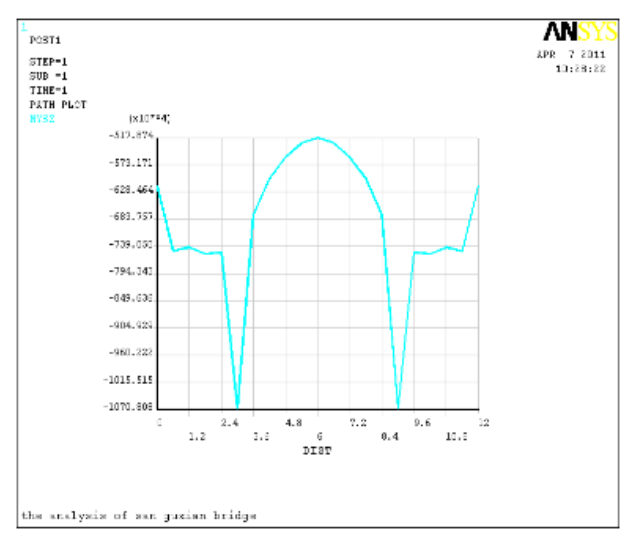

Fig. 17 - Longitudinal stress along the top flange of main pier

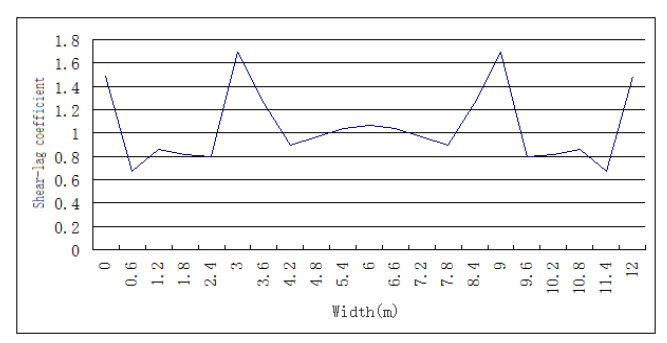

Fig. 19 - Shear-lag coefficient along the top flange of midspan

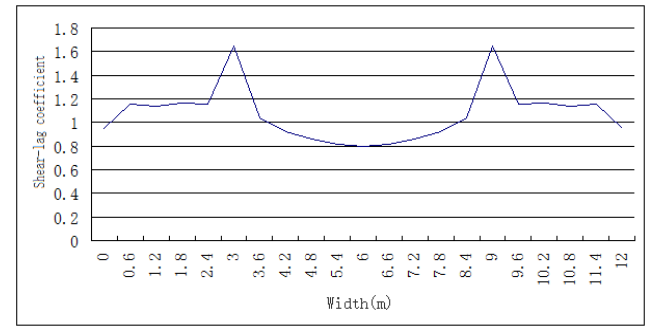

Fig. 21 - Shear-lag coefficient along the top flange of main pier

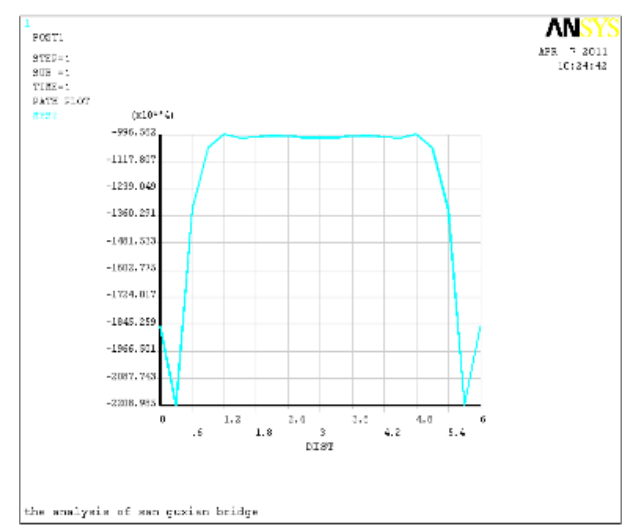

Fig. 16 - Longitudinal stress along the bottom flange of midspan

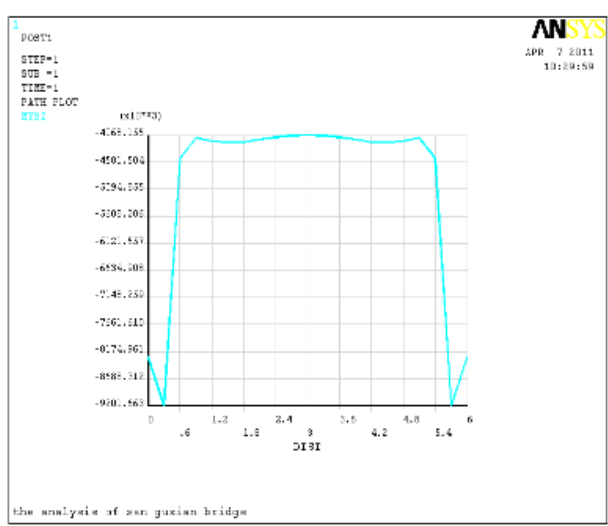

Fig. 18 - Longitudinal stress along the bottom flange of main pier

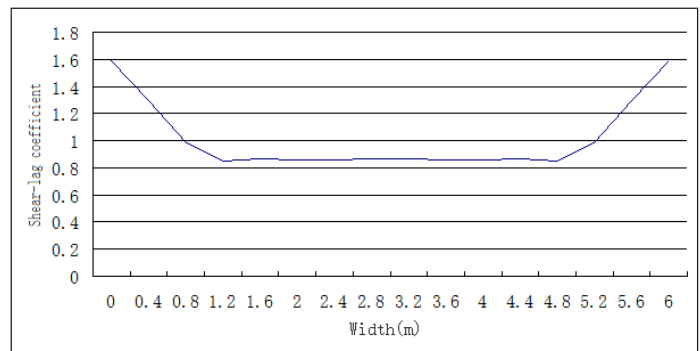

Fig. 20 - Shear-lag coefficient along the bottom flange of midspan

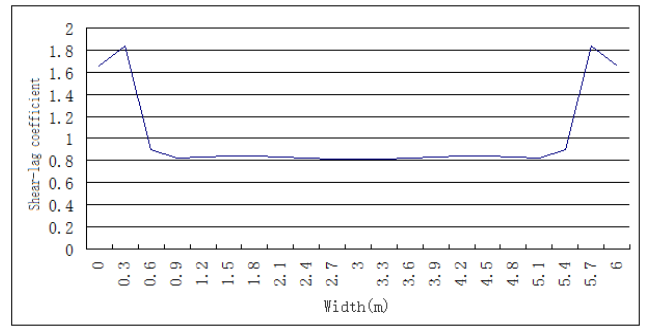

Fig. 22 - Shear-lag coefficient along the bottom flange of main pier 
Article no. 48

CIVIL

ENGINEERING

JOURNAL

THE CIVIL ENGINEERING JOURNAL 3-2021

\section{LOAD TEST ANALYSIS}

According to the requirements of design specifications [13], the maximum effect of the combination of bending moment and shear force is considered in the test condition. The measuring points arrangement is shown in Figure 23 and Figure 24.

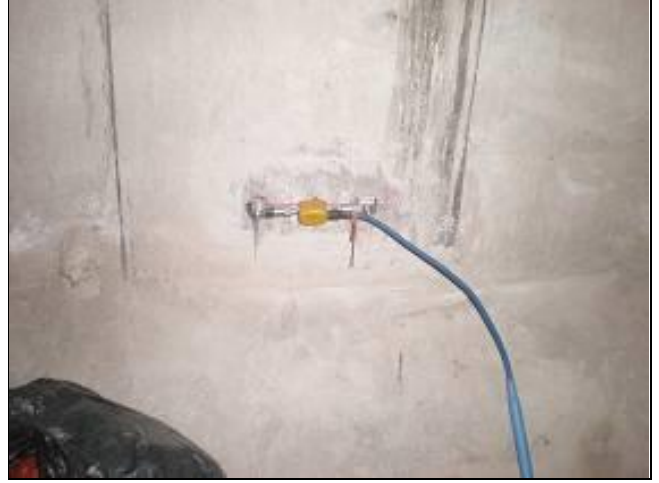

(a)

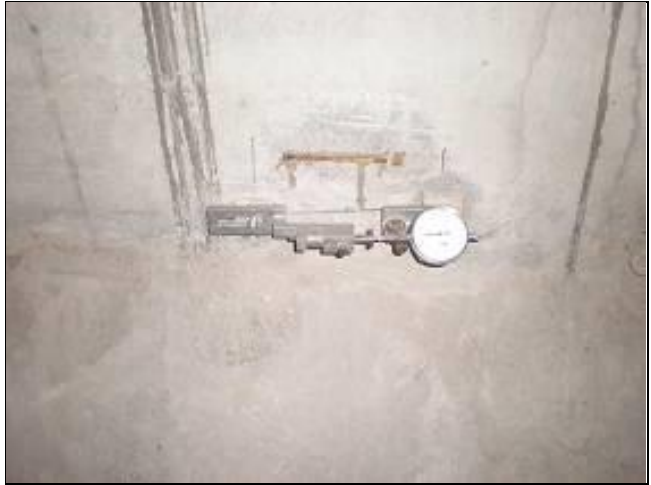

(b)

Fig. 23 - Measuring points arrangement of longitudinal stress

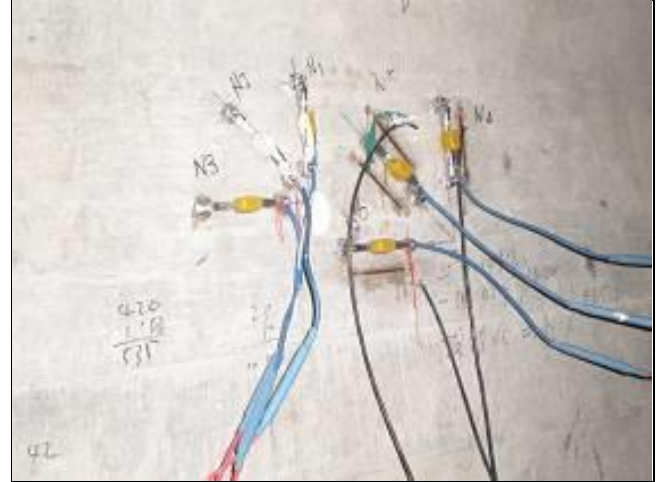

(a)

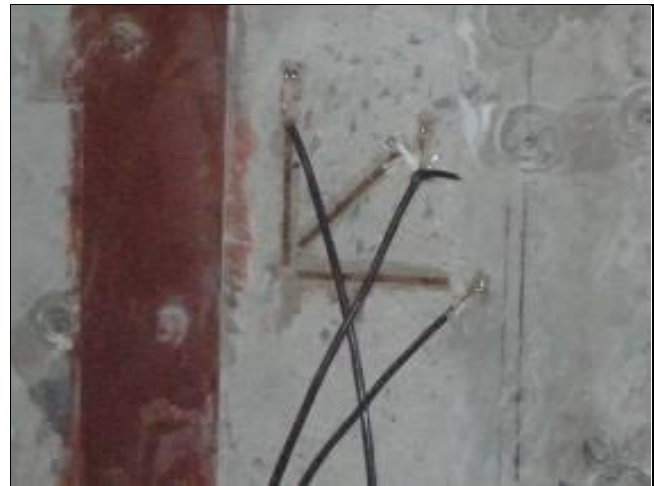

(b)

Fig. 24 - Measuring points arrangement of principal stress

The test results are shown in the tables and figures below. It can be seen that the theoretical calculation of longitudinal stress and principal stress have the same law as the test results, and the results are basically consistent with less error. In general, the results of spatial calculation are smaller than those of plane calculation. The maximum longitudinal stress difference is $0.35 \mathrm{MPa}$, and the principal stress is $0.34 \mathrm{MPa}$. The spatial calculation are closer to the test results, which indicates that the spatial finite element model established in this paper accords with the practice and the theoretical calculation results are reliable. At the same time, the calculation of the spatial model is slightly larger than the test results, so the calculation is somewhat safe. 
Tab.1 - Test results of longitudinal stress (unit: $\mathrm{MPa}$ )

\begin{tabular}{|c|c|c|c|c|c|c|}
\hline \multicolumn{2}{|c|}{ Test position } & $\begin{array}{c}\text { Test } \\
\text { result }\end{array}$ & $\begin{array}{c}\text { Plane } \\
\text { calculation }\end{array}$ & $\begin{array}{c}\text { Spatial } \\
\text { calculation }\end{array}$ & $\begin{array}{c}\text { Plane / } \\
\text { Spatial }\end{array}$ \\
\hline \multirow{2}{*}{$\begin{array}{c}\text { Negative moment } \\
\text { for pier 1 }\end{array}$} & 1 & Top flange & 0.17 & 0.69 & 0.44 & 1.57 \\
\cline { 2 - 7 } & 2 & Bottom flange & -0.86 & -1.35 & -1.12 & 1.21 \\
\hline \multirow{2}{*}{$\begin{array}{c}\text { Negative moment } \\
\text { for pier 2 }\end{array}$} & 3 & Top flange & 0.35 & 0.80 & 0.72 & 1.11 \\
\cline { 2 - 7 } & 4 & Bottom flange & -0.41 & -0.70 & -0.51 & 1.37 \\
\hline \multirow{2}{*}{\begin{tabular}{c} 
Midspan for span 2 \\
\cline { 2 - 7 }
\end{tabular}} & 5 & Top flange & -0.63 & -1.04 & -0.71 & 1.46 \\
\hline \multirow{2}{*}{$\begin{array}{c}\text { Midspan for main } \\
\text { span }\end{array}$} & 7 & Bottom flange & 1.27 & 1.74 & 1.39 & 1.25 \\
\cline { 2 - 7 } & 8 & Web & 1.01 & 1.66 & 1.56 & 1.06 \\
\hline
\end{tabular}

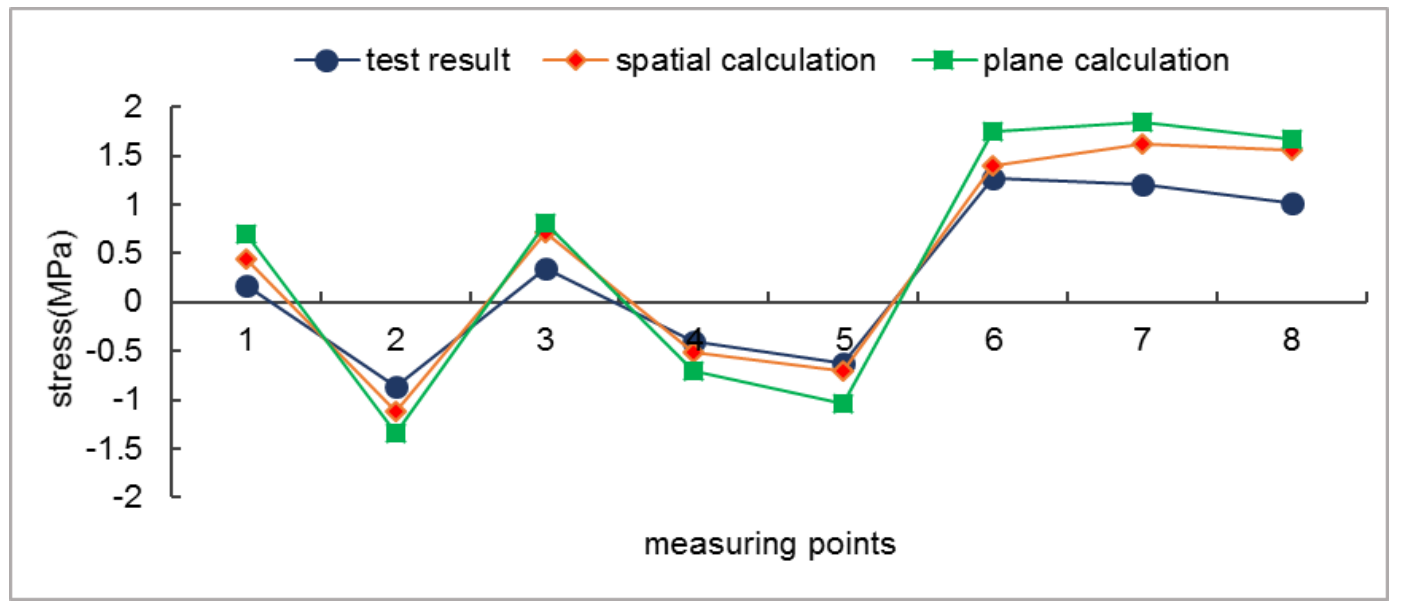

Fig. 25 - Longitudinal stress line chart

Tab. 2 - Test results of principal stress (unit: MPa)

\begin{tabular}{|c|c|c|c|c|c|c|c|c|}
\hline \multirow{2}{*}{ Test position } & \multirow{2}{*}{$\begin{array}{l}\text { Measuring } \\
\text { points }\end{array}$} & \multicolumn{3}{|c|}{ Strain $(\mu \varepsilon)$} & \multirow{2}{*}{$\begin{array}{l}\text { Test } \\
\text { result }\end{array}$} & \multirow{2}{*}{$\begin{array}{c}\text { Plane } \\
\text { calculation }\end{array}$} & \multirow{2}{*}{$\begin{array}{c}\text { Spatial } \\
\text { calculation }\end{array}$} & \multirow{2}{*}{$\begin{array}{l}\text { Plane } \\
\text { /Spatia }\end{array}$} \\
\hline & & $0^{\circ}$ & $45^{\circ}$ & $90^{\circ}$ & & & & \\
\hline \multirow{2}{*}{$\begin{array}{l}\text { 5\# segment for } \\
\text { span } 2\end{array}$} & 1 & 12.40 & 6.40 & 20.80 & 0.95 & 1.17 & 1.38 & 1.18 \\
\hline & 2 & 30.10 & 17.2 & -23.00 & 1.15 & 1.38 & 1.52 & 1.10 \\
\hline \multirow{2}{*}{ Top for pier 2} & 3 & 0.41 & 1.47 & -5.50 & 0.18 & 0.22 & 0.29 & 1.32 \\
\hline & 4 & 3.70 & -1.50 & -2.20 & 0.35 & 0.42 & 0.49 & 1.17 \\
\hline \multirow{2}{*}{$\begin{array}{l}5 \# \text { segment for } \\
\text { main span }\end{array}$} & 5 & 5.70 & -49.40 & -33.20 & 0.93 & 1.24 & 1.58 & 1.27 \\
\hline & 6 & -20.40 & -70.90 & -30.30 & 0.71 & 1.02 & 1.32 & 1.29 \\
\hline
\end{tabular}




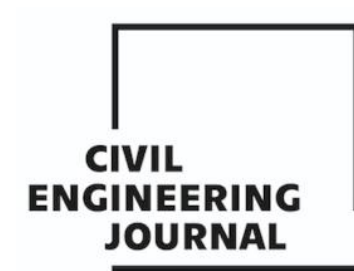

Article no. 48

THE CIVIL ENGINEERING JOURNAL 3-2021

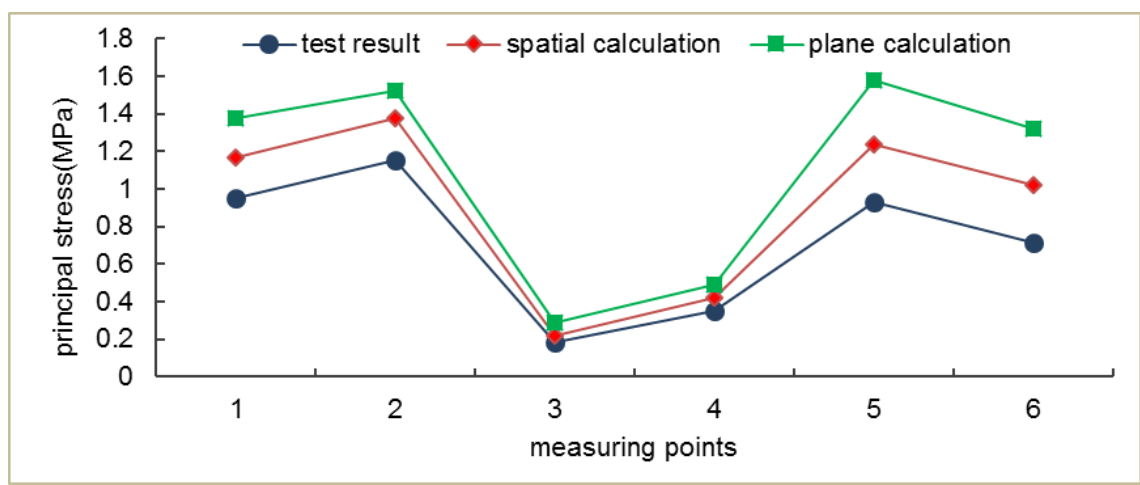

Fig.26 - Principal stress line chart

\section{CONCLUSION}

Based on the research results, the following conclusions can be drawn:

(a) The top and bottom flange are under longitudinal compression, and the longitudinal stress is evenly distributed along the width direction, which indicates that the spatial stress effect and shear lag effect have little influence on the down deflection of the bridge.

(b) The stress at the main pier within the webs is abrupt, and it is easy to crack. Due to the influence of shear lag effect, the main stress from the longitudinal axis of the bottom flange to the web gradually decreases, and the stress concentration occurs at this place, where transverse cracks are more likely to occur than both sides.

(c) The top and bottom flange of the main span and the main pier are positive shear lag effect. The shear lag coefficient of the top flange at midspan is between 0.7 and 1.7, and that of bottom flange is between 0.85 and 1.6. As the main pier, the shear lag coefficient of top flange is between 0.8 and 1.65, and that of bottom flange is between 0.8 and 1.82. Under the action of deadweight and prestress, the longitudinal stress of box girder is distributed unevenly in the transverse direction, and the dispersion degree of shear lag coefficient is larger in top flange than that in bottom flange.

(d) The spatial calculations are closer to the test results than those of plane calculations, the maximum longitudinal stress difference is $0.35 \mathrm{MPa}$, it indicates that the spatial finite element analysis is more practical and reliable. Moreover, the spatial calculations analysis are generally larger than the test results, so it is safe to carry out design and construction according to the spatial finite element analysis.

(e) The shear lag coefficient reaches its maximum value at the intersection of the top and bottom flange with web, and decreases to both sides. In the design and construction stage, the cracking and bending situation of this position should be fully considered, and the strengthening treatment should be carried out here. And reasonable arrangement of prestressed and structural reinforcement to prevent cracks caused by stress concentration. For bridges that have been cracked and flexed down, external prestress or steel plate can be used to reinforce them. Cracks should be treated before reinforcement. If the number of external prestressing steel strand is numerous, the scheme of dispersed arrangement along the top and bottom flange can be adopted. 


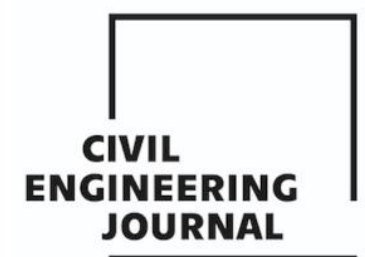

Article no. 48

THE CIVIL ENGINEERING JOURNAL 3-2021

\section{REFERENCES}

[1] Guo JM. Design Theory of Box Girder[M]. Beijing: China Communications Press, 1999.

[2] Peng W, Xing HY, Ke SG. Study on Cracking Control of PC Continuous Box Girder Bridges[J]. Journal of Zhejiang Universitr of Technology, 2003, 31(1): 22-27.

[3] Li Z, Nie JG, Ji WY. Positive and Negative Shear Lag Behaviors of Composite Twin-Girder Decks with Varying Cross-Section[J]. Science China Technological Sciences, 2017, 60(1): 116-132.

[4] Lin PZ, Liu FK, Ji W, et al. Analysis on Shear Lag Effect of Concrete Box Beam by Variation Principle[J]. Journal of The China Railway Society, 2013, 35(2): 93-98.

[5] Guo ZW, Li LJ, Zhang JB. Theoretical Analysis for Shear-lag Effect of Variable Box Section Cantilever Girder Based on Bar Simulation Method[J]. China Civil Engineering Journal, 2019, 52(8): 72-80.

[6] Cambronero-Barrientos F, Díaz-Del-Valle J, Martínez-Martínez JA. Beam Element for Thin-Walled Beams with Torsion, Distortion and Shear Lag[J]. Engineering Structures, 2017, 143: 571-588.

[7] Ma C, Liu SZ, Wu MQ. Matrix Analysis of Composite Box Girder with Corrugated Steel Webs Considering Shear Deformation and Shear Lag Effect[J]. China Journal of Highway and Transport, 2018, 31(3): 80-88.

[8] Feng HY. The Analysis of Space Stress and Shear Lag Effect of Prestressed Concrete Thin-Walled Box Girder Bridge[D]. Harbin: Northeast Forestry University, 2011.

[9] Zhao H, Gou HY, Ni YS. Shear Lag Effect of Corrugated Steel-Concrete Composite Multi-Box CableStayed Bridge[J]. Journal of South China University of Technology (Natural Science Edition), 2020, 48(7): 93-103.

[10] Xu D, Ni YS, Zhao Y. Analysis Corrugated Steel Web Beam Bridges Using Spatial Grid Modeling[J]. Steel and Composite Structures, 2015, 18(4): 853- 871.

[11] Zhang, Zhongwen, $\mathrm{Li}$, et al. Effects of the shear lag on longitudinal strain and flexural stiffness of flanged RC structural walls[J]. Engineering Structures, 2018.

[12] Lin PZ,Sun LX,Yang ZJ, et al. Research on Shear Lag Effect of Twin-Cell Box Girders[J]. Journal of Railway Engineering Society, 2014(1): 59-60.

[13] CCCC Highway Consultants Co., Ltd, Specifications for Design of Reinforced Concrete and Prestressed Concrete Highway Bridges and Culver (JTJ 023-85) [M]. Beijing: China Communications Press, 1985.

[14] Tan D, Li X. Analysis of Wide Box Gird's Shear-lag Effect Based on Energy Method in Single-Cableplane Cable Stayed Bridge[J]. IOP Conference Series Materials Science and Engineering, 2020, 768: 032044.

[15] Duan HJ, Zhao RD. Segment Element of Thin-Walled Curved Box Girder by Spatial Analysis[J]. China Civil Engineering Journal, 2004, 37(12): 1-5. 